\title{
An Assessment of the Effect of Team Building on Team Performance in Gutu District, Masvingo Province, 2010
}

\author{
Pomerai $\mathrm{KW}^{1 *}$, Mudyiradima $\mathbf{R F}^{2}$ and Chadambuka $\mathbf{A}^{\mathbf{1}}$ \\ ${ }^{1}$ Department of Community Medicine, Zimbabwe \\ ${ }^{2}$ Masvingo Provincial Medical Directorate, Zimbabwe \\ *Corresponding author: Pomerai KW, Department of Community Medicine, Zimbabwe \\ Submission: 眥 August 22, 2017; Published: 眥 January 25, 2019
}

\begin{abstract}
Introduction: Lack of team work is a major problem in civil service in Zimbabwe. Poor team work leads to reduced performance in a team. Gutu district performed very little for the past three years and a baseline survey showed lack of team work. This study aimed to assess the effectiveness of team building on team performance.
\end{abstract}

Methods: A before and after quasi experimental study was conducted. District managers were study participants. A baseline survey was conducted to determine views on key leadership issues, such as convening meetings, managing conflict, planning and communication. Next, a five-day team building retreat was conducted in a secluded area away from the district. After the team building exercise, participants were observed for three months to assess improvement in planning, convening meetings, supervision, and outbreak response. A post intervention survey was conducted to after the intervention.

Results: All six district health managers participated, none of them had been trained in management, there was improvement in holding meetings, and writing reports reduced conflicts. All managers assisted other managers achieve their goals.

Conclusion: Team building has an effect on team performance on Gutu health managers

Keywords: Team building; District health executive; Gutu; Zimbabwe

\section{Introduction}

A team comprises a group of people or animals linked in a common purpose. Teams are especially appropriate for conducting tasks that are high in complexity and have many interdependent subtasks.

A group in itself does not necessarily constitutes a team Teams normally have members with complementary skills and generate synergy through a coordinated effort which allows each member to maximize his or her strengths and minimize his or her weaknesses. Team members need to learn how to help one another, help other team members realize their true potential, and create an environment that allows everyone to go beyond their limitations [1]. Thus, teams of sports players can form (and re-form) to practice their craft. Transport logistics executives can select teams of horses, dogs or oxen for the purpose of conveying goods. Teams, such as in medical fields, may be interdisciplinary or multidisciplinary. Multidisciplinary teams involve several professionals who independently treat various issues a patient may have, focusing on the issues in which they specialize. The problems that are being treated may or may not relate to other issues being addressed by individual team members. Interdisciplinary team approach involves all members of the team working together towards the same goal. In an interdisciplinary team approach, there can often be role blending by members of the core team, who may take on tasks usually filled by other team members [2]. In the Ministry of Health and Child Welfare (MOHCW) the district public health activities are run by a team called District Health Executive (DHE). This team comprises of the District Medical Officer (DMO) who is the team leader or manager and chairs the DHE meeting. Other members are the District Nursing officer (DNO) who is a senior nurse or nursing manager, District Environmental Health Officer (DEHO) who is a health inspector, District Health Services Administrator (DHSA) who heads administration department, Health Promotion Officer (HPO), Pharmacist, Lab Scientist, Nutritionist. Other members can be co-opted members chosen by the DMO. The DHE came into being so that there can be decentralization of health services management. Under the guidance and leadership of the DMO the DHE runs the entire district health services delivery and reporting to the Provincial Medical Director (PMD). The PMD heads a Provincial Health Executive (PHE) team comprising of the same professions as in DHE and reports to the Permanent Secretary of the Ministry of Health [3]. 
The functions of the DHE are among many other budgeting, planning, decision making and policy implementation at district level. If DHE is not functional, then the vision and mission of the Ministry of Health will not be accomplished as the DHE must guide and direct the District Health Team (DHT). The DHT comprises every health worker in the district; DHEs came into being to improve service delivery by decentralization [3]. Creating an effective team is a challenging exercise in every organization and this process is called team building. Team building involves a wide range of activities presented to organization for improving team performance. Team building ranges from simple bonding exercises to complex simulations and multi day to day team building retreats, team building can also mean selecting or creating a team from scratch [4]. Gutu District was performing the worst out of the seven districts in Masvingo Province. In 2010 the district failed to hold a single of the following meetings: DHE meeting, Heads of Department meeting, Transport meeting, District Health Team meeting held once quarterly, disease surveillance meeting held once weekly, procurement meeting and a budgeting meeting. They failed to come up with a costed Results Based Management (RBM) plan. No progress reports were written from the district. All activities are not properly coordinated. The PHE team had provided support and supervision to the DHE six times that year but no improvement was realized. We implemented a team building exercise as an intervention and determined its effect on the performance of the DHE.

\section{Materials and Methods}

A quasi experimental study (before and after) was carried out with the Gutu District Health Executive. The DHE was blinded to the reason of the team building exercise in order to prevent artificial behavior during the observation period.

\section{Pre-intervention survey}

A pre-intervention survey (situational analysis) was conducted using a questionnaire that was administered to the DHE members. This survey elicited problems related to how the team was functioning. The issues identified were then used to design a team building training package to address causes of team malfunction observed.

\section{Description of the intervention}

Two skilled team building experts facilitated the team building exercise. A five-day team building retreat was done. DHE members were taken away from the usual workplace to a private place where they were alone with team building facilitators. During the exercise the team was taken through trust building by leading each other while blind folded, they were paired and made to play simple games that involved novel complex tasks, cooked for each other and made each other's beds. They went for ropes courses, cooperate drumming and physical exercises. Activities geared to improve communication skills were conducted through exercises and games that highlighted the need for good, strategic and effective communication in team performance or potential problems with communication. Problem solving and decision-making exercises were done, and this focused on groups working together to solve hypothetical complex problems or make complex decisions. Psychological analysis of team roles and training on how to work better together were done and going through each member's job description. Budgeting, planning, and communication trainings were done, and time created so that the team will have time to know each other better in a friendly environment. The DHE was then observed for a period of three months (January to March 2010) for changes in performance.

\section{Post-intervention survey}

A post-intervention survey was conducted using the same instrument for the pre-intervention survey after 3 months of observation. The changes in performance of the DHE were then computed.

\section{Outcomes of interest}

The outcomes of interest were completing plans, holding meetings (e.g. DHE, DHT, HOD), conducting support and supervision as DHE team, writing reports, using purchase plans, transport schedules and controlling outbreak as a team.

\section{Hypothesis}

$\mathrm{H}_{0}: \mu \mathrm{d} \leq 0$ Team building does not increase number of meetings

$\mathrm{H}_{1}: \mu \mathrm{d}>0$ Team Building effective in increasing number of meetings

All six DHE members in Gutu were recruited and participated in the study.

Microsoft Excel was used to generate frequencies and means and calculate intervention impact size

\section{Results}

The demographic characteristics of study participants are shown in Table 1. Two of them had degrees and four had diplomas, the median years in services was 29 years $\left[Q_{1}=; Q_{3}=\right]$ and four were substantively appointed on their posts. All (6) DHE members knew the composition and roles of the DHE roles was very high among the members, some of the roles that were reported were: planning and coordinating public health activities(6), Formulation and implementation of polices(6), budgeting for the district(6), Control of resources(6), Monitoring and evaluation of public health activities(6), and bidding for staff(6) though all the DHE members reported that the DHE was not performing its duties. All team members reported lack of team work as a reason for failure of the DHE to perform its tasks as shown in Table 1. All DHE members reported that the problems the DHE was facing can be solved and could be solved through team building. None of the DHE members knew the other members roles in the DHE and none were inducted when assuming their posts. Only one member reported assisting other team members attain their goals. 
Table 1: Assessment of effect of intervention on the members in gutu district 2011.

\begin{tabular}{|c|c|c|}
\hline Response of DHE Members & N=6 Before Intervention & N=6 After Intervention \\
\hline Knowledge of composition of DHE & 6 & 6 \\
\hline Knowledge of roles of DHE & 6 & 6 \\
\hline DHE performing its roles & 0 & 0 \\
\hline Reasons for DHE not performing its roles & & 0 \\
Lack of team work & 6 & 0 \\
Lack of leadership & 6 & 0 \\
\hline Mistrust & 6 & 0 \\
\hline Conflicts & 6 & 6 \\
\hline Team building can solve the problems & 6 & 6 \\
\hline Knowledge of other team members duties & 6 & 0 \\
\hline Inducted when assuming current post & 0 & 5 \\
\hline
\end{tabular}

The team was now making decisions and agreeing on them and implement them for example they agreed on purchasing airtime for surveillance in the district, discussed and agreed to service motorcycles, the issue of motorcycle servicing was a stalemate since 2009. Transport schedules were now being used as they were never in use before, consolidated district purchase plan was formulated and used in 2011 this plan was last drafted in 2006. CBU and PTC meeting were now being used to adjudicate tenders and identify reputable suppliers unlike before when they were no CBU and PTC meetings (Table 2). Ten conflicts were reported in the first quarter the number of conflicts reported to the province was reduced to zero unlike in 2010. The DHE supervised health centers in its jurisdiction once that quarter unlike before when the supervision was individual, and no reports written (Table 3). The DHE wrote 3 consolidated monthly reports to the province as compared to 2010 when they failed to write a report to the province. No outbreak was reported during the observation phase Table 4.

Table 2: Assessment of the effectiveness of team building on holding meetings on gutu DHE in 2011.

\begin{tabular}{|c|c|c|c|c|c|}
\hline Activity & \multicolumn{2}{|c|}{ Before Intervention } & \multicolumn{2}{c|}{ After Intervention } & Intervention Effect Size \\
\hline Expected DHE meetings & Expected Number of meetings/quarters & Number held & $\begin{array}{c}\text { Expected } \\
\text { meetings }\end{array}$ & $\begin{array}{c}\text { Number } \\
\text { held }\end{array}$ & Intervention effect size \\
\hline DHE & 12 & 0 & 12 & 12 & 12 \\
\hline Expected Weekly surveillance & 12 & 0 & 12 & 12 & 12 \\
\hline PTC meetings & 12 & 0 & 12 & 9 & 9 \\
\hline CBU & 12 & 0 & 12 & 9 & 3 \\
\hline HOD meeting & 3 & 0 & 3 & 3 & 1 \\
\hline DHT meeting & 1 & 0 & 1 & 3 & 3 \\
\hline Transport Planning meeting & 3 & 0 & 3 & 3 & \\
\hline Full council & 3 & 0 & 3 & 3 & 3 \\
\hline RDDC & 3 & 0 & 3 \\
\hline
\end{tabular}

Table 3: Assessment of team building on report writing and submission to province by gutu DHE 2011.

\begin{tabular}{|c|c|c|c|c|c|}
\hline Report & $\begin{array}{c}\text { Expected Number/ } \\
\text { Quarter }\end{array}$ & $\begin{array}{c}\text { No. of Reports Submit- } \\
\text { ted }\end{array}$ & $\begin{array}{c}\text { Expected No./ } \\
\text { Quarter }\end{array}$ & $\begin{array}{c}\text { No. of Reports Sub- } \\
\text { mitted }\end{array}$ & $\begin{array}{c}\text { Intervention } \\
\text { Effect Size }\end{array}$ \\
\hline District monthly report & 3 & 0 & 3 & 3 & 3 \\
\hline District quarterly report & 1 & 0 & 1 & 1 & 1 \\
\hline $\begin{array}{c}\text { Quarterly support and } \\
\text { supervision }\end{array}$ & 1 & 0 & 1 & 1 & 1 \\
\hline
\end{tabular}

Table 4: Comparison of management meetings held by Gutu DHE before and after team building 2011.

\begin{tabular}{|c|c|c|c|c|c|c|c|c|c|}
\hline Type of Meeting & DHE & WDSS & CBU & PTC & HOD & DHT & Transport & Full Council & RDDC \\
\hline Before & 0 & 0 & 0 & 0 & 0 & 0 & 0 & 0 & 0 \\
\hline After & 12 & 12 & 9 & 9 & 3 & 1 & 3 & 3 & 3 \\
\hline Degrees of freedom & 12 & 12 & 9 & 9 & 3 & 1 & 3 & 3 \\
\hline
\end{tabular}


Paired t test for management meetings held by Gutu DHE before and after team building. Degrees of freedom shown in Table 4.

Decision rule: $\alpha$ 0,1, $(\mathrm{n}-1)=(9-1)=8$

Therefore: $\mathrm{t}$ crit $=1,397$

Therefore, reject $\mathrm{H}_{0}$ if $\mathrm{t}$ cal $\geq t$ critic which is $\geq 1,397$

$d=12+12+9+9+3+1+1+3+3+3 / 9$

$=55 / 9$

$=6.11$

$\mathrm{Sd}^{2}=\sum\left(\mathrm{d}_{\mathrm{i}}-\mathrm{d}\right)^{2} /(\mathrm{n}-1)$

$=34,69+34.69+8,35+8,35+9,67+26,11+9,67+9,67+9,67 / 8$

$=150.87 / 8$

$=18.86$

$\mathrm{T}=\mathrm{d}-\mu \mathrm{d} / \mathrm{sd}=6.11-0 /$ square root of 18.86

$=6.11 / 4.34$

$=1.4078\left(\mathrm{t}\right.$-calc) is greater than $>\mathrm{t}$ crit 1.3971 reject $\mathrm{H}_{0}$ in favour of $\mathrm{H}_{1}$ and conclude that team building is effective in increasing number of meetings and the results are statistically significant with a $p$ value less than 0,1 .

\section{Discussion}

Knowledge on the roles and composition of the DHE was high among, this could be since majority of the members had long years in service and could have heard about them in workshops and other literature at the workplace. Majority of the members had not been inducted on the job post they were occupying; this may have led to frequent frictions between the DHE members and may have led to poor team work. Induction would have helped the team members know their roles and as well as the other members roles. It is the responsibility of the members to come together and plan out a way that would lead them to their target successfully [5]. During the team building exercise the members were taught of importance of holding meetings, how to hold successful meeting and time management, these lectures might have led to the constant holding of meetings by the team and participation is reflected by the minutes that are sent to the PMD office were all members are taking part in discussions and decision making. The use of purchase plans and adhering to procurement procedures that is being experienced in Gutu might be attributed to the lectures on effective and cost cutting procurement that the team received while at team building. The improved decision making that was not seen in Gutu that is being experienced now can be attributed to the solving hypothetical complex problems games that the team carried out during the team building activity. Time management lectures may have led to the production and use of work plans by the team members as this was done before.

The formulation of transport schedules and combining trips that is being done in Gutu may be attributed to the lectures the team received on effective transport management in health delivery and all the members reported that they are now comfortable with travelling with one another since they got used to it during the team building activity of tour drives which made the team members interact on social basis during drives to view nature and animals at recreational parks. Combining trips saves fuel and mileage of vehicles which we may later translate to money saving. Team members must work in unity to achieve targets that have been set for them. Lack of leadership was reported by all the members. The team leader is supposed to provide technical and professional expertise to the team members so that they achieve their goals, but when leadership is seen as lacking by the team members, they begin to undermine the leader and start to operate in an unorganized manner that may be detrimental to the organization. One thing the leader and the team members have to understand is that human beings by nature have different personalities and attitudes and while working in a team these opinions and personalities may clash and give rise to conflicts within the team.

Communication was reported to be another factor that affected team work in Gutu, we noted that this was lacking and was reported as another reason for poor team work. For the success of any team communication is essential, the team leader is the one who makes decisions but this does not mean that he/she must no listen to any other team members the team leader should encourage participation by other team members ion discussions and come up with a collective way to follow so that they achieve their goal, regular meetings should be held to review development and every member should contribute ideas for the success of the team [5-7]. This helps boost the morale of the team members and understand their progress at work. There were several conflicts that were reported from Gutu in 2009 and 2010 and this may have led to the poor team work that was reported by the team members, this is supported by a study that was conducted in Kenya which revealed that conflict made teams ineffective and sloppy [8].

Effective communication lectures may be attributed to the improved horizontal and vertical communications that are being done by the members through reports, memo and phone calls as well as meeting. There has not been a conflict reported from the team to the province since the intervention. The reduction in friction and conflicts among members may be attributed to the likes and dislike activity were the teams had to mention what they like and dislike both at work and in social life [9]. The members might now approach each other knowing what the other member likes and dislikes, reduction in conflicts reported to province may also be due to the communication training that was done and still being reinforced between the members. The other change though difficult to objectively measure was the improved trust among the members which may have been improved by blind folding games and the cooking and dishing food for each other the team members did during team building. We recommended maintaining post intervention support and observation for the DHE team in Gutu DHE for one year.

\section{Conclusion}

Team building was effective on team performance in Gutu. Therefore, we reject Null hypothesis which state that team building 
has no effect on improving performance on Gutu DHE 2011 in favour of Alternative hypothesis which sated that team building improves team performance on Gutu DHE 2011.

\section{References}

1. Davis Barbee (2009) 97 things every project manager should know: collective wisdom from the experts. In: Nitin (Ed.), Build teams to Run Marathons, Not Sprints O’Reilly, Beijing, China, p. 96.

2. Ferrell $A B$, Betty, Nessa Coyle (2006) Textbook of palliative nursing $\left(2^{\text {nd }}\right.$ edn), Oxford University Press, USA, p. 35

3. Provincial Health Services Administrator (PHSA), Personal Communication Masvingo Province, Zimbabwe.

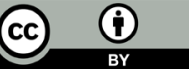

Creative Commons Attribution 4.0 International License

For possible submissions Click Here

\section{Submit Article}

4. http://en.wikipedia.org/wiki/

5. http://www.buzzle.com/articles/how-to-improve-teamwork.html

6. Ham C (1997) Priority setting in health care: learning from the international experience. Health policy 42(1): 49-66.

7. Kleinman CS (2004) Leadership strategies in reducing staff nurse role conflict. JONA 34(7-8): 322-324.

8. Owino W, Odundo P, Oketch T (2001) Governance of district health systems: a focus on the health management boards and human resource development issues.

9. Thomson J (2017) The Effectiveness of the Concept of Team Building.

\begin{tabular}{|c|c|c|}
\hline \multirow[t]{7}{*}{ IGRWH } & $\begin{array}{l}\text { Investig. } \\
\text { gyesecol } \\
\text { skame }\end{array}$ & $\begin{array}{c}\text { Investigations in Gynecology Research \& Womens } \\
\text { Health }\end{array}$ \\
\hline & & Benefits of Publishing with us \\
\hline & & - High-level peer review and editorial services \\
\hline & & - Freely accessible online immediately upon publication \\
\hline & & - Authors retain the copyright to their work \\
\hline & & - Licensing it under a Creative Commons license \\
\hline & & - Visibility through different online platforms \\
\hline
\end{tabular}

